\title{
Các tính chất kỹ thuật và đặc điểm vi cấu trúc của vữa xây dựng được chế tạo bằng phương pháp kiềm hoạt hóa
}

\author{
Huỳnh Trọng Phước ${ }^{1 *}$, Đỗ Minh Thiện ${ }^{1}$, Huỳnh Hoàng Phong1, Lê Thị Thanh Tâm², Lê Văn Quang ${ }^{3}$ \\ ${ }^{1}$ Trường Đại học Cần Thơ; Khu II, đường 3/2, quận Ninh Kiều, thành phố Cần Thơ \\ ${ }^{2}$ Trường Đại học Hồng Đức; Số 565 Quang Trung, phường Đông Vệ, thành phố Thanh Hóa \\ ${ }^{3}$ Viện Vật liệu Xây dựng; Số 235 Nguyễn Trãi, phường Thanh Xuân Trung, quận Thanh Xuân, thành phố Hà Nội \\ TỪ KHOÁ

\section{TÓM TẮT}

Vữa xây dựng

Tro bay

Xỉ lò cao nghiền mịn

Phương pháp kiềm hoạt hóa

\section{KEYWORDS}

\section{Cementless mortar}

Fly ash

Ground granulated blast-

furnace slag

Alkaline activation method
Bài báo này trình bày kết quả nghiên cứu tận dụng nguồn chất thải tro bay và phụ phẩm xỉ lò cao nghiền mịn từ các nhà máy nhiệt điện và luyện kim ở Việt Nam trong chế tạo vữa xây dựng bằng phương pháp kiềm hoạt hóa với định hướng ứng dụng cho hoạt động xây tô hoàn thiện công trình. Các mẫu vữa được thiết kế với mác yêu cầu tối thiểu M10 sử dụng các tỉ lệ khác nhau (theo khối lượng) của xỉ lò cao/tro bay $(70 / 30,50 / 50$ và $30 / 70)$ và các nồng độ khác nhau của dung dịch $\mathrm{NaOH}(6 \mathrm{M}, 8 \mathrm{M}$, $10 \mathrm{M}$ và $12 \mathrm{M}$ ). Hỗn hợp hai dung dịch $\mathrm{NaOH}$ và $\mathrm{Na}_{2} \mathrm{SiO}_{3}$ được sử dụng làm dung dịch kiềm kích hoạt trong nghiên cứu này. Các đặc tính kỹ thuật của các mẫu vữa được đánh giá gồm cường độ chịu nén, độ hút nước, độ co khô, tốc độ truyền sóng siêu âm qua mẫu và phân tích đặc điểm vi cấu trúc vữa trên cơ sở đối sánh với các tính chất tương ứng của mẫu vữa xi măng thông thường. Kết quả thực nghiệm cho thấy, mẫu vữa được sản xuất từ $50 \%$ tro bay $+50 \%$ xỉ lò cao và được kích hoạt bằng dung dịch kiềm có sử dụng $\mathrm{NaOH} 10 \mathrm{M}$ (S5F5N10) có các tính chất kỹ thuật phù hợp nhất với yêu cầu của vữa xây dựng theo TCVN 4314:2003. Kết quả nghiên cứu một lần nữa khẳng định tiềm năng lớn trong sản xuất vữa xây dựng sử dụng tro bay và xỉ lò cao, có thể thay thế hoàn toàn vữa xi măng truyền thống trong các hoạt động xây dựng, góp phần tiết kiệm nguồn tài nguyên thiên nhiên và hạn chế tình trạng ô nhiễm môi trường.

\begin{abstract}
This paper presents the results of the study on the use of fly ash (FA) and ground granulated blast-furnace slag (GGBFS) in the preparation of construction mortars by alkaline activation method with application orientation for plastering works. The mortar samples were designed with a target compressive strength value of at least $10 \mathrm{MPa}$ at 28 days using different mass ratios of GGBFS/FA (70/30, 50/50, and 30/70) and various concentrations of $\mathrm{NaOH}$ solution $(6 \mathrm{M}, 8 \mathrm{M}, 10 \mathrm{M}$, and $12 \mathrm{M})$. A mixture of $\mathrm{NaOH}$ and $\mathrm{Na}_{2} \mathrm{SiO}_{3}$ solutions was used as an alkaline solution. Characteristics of the mortar samples were assessed including compressive strength, water absorption, drying shrinkage, ultrasonic pulse velocity, and microstructure analysis. A comparison between the properties of the alkali-activated mortar and the traditional cement mortar was performed in this study. Experimental results show that the mortar samples produced using 50 $\% \mathrm{FA}+50 \%$ GGBFS that activated by the $\mathrm{Na}_{2} \mathrm{SiO}_{3}+\mathrm{NaOH} 10 \mathrm{M}$ exhibited the most suitable engineering properties among the mixtures according to TCVN 4314:2003. Further, the results of the study demonstrate great potential in producing alkali-activated construction mortar using FA and GGBFS, which can completely replace traditional cement mortar in construction activities, contributing to both saving natural resources and limiting environmental pollution.
\end{abstract}

\section{Giới thiệu}

Trong những năm gần đây, ngành xây dựng đã có nhiều bước tiến đáng kể theo hướng hiện đại ở hầu hết các lĩnh vực như, xây dựng công trình, vật liệu xây dựng (VLXD), kiến trúc và quy hoạch xây dựng, phát triển đô thị và nhà ở, v.v. Nhu cầu xây dựng trong nước cũng đang rất lớn, đòi hỏi một lượng lớn tương ứng của các loại VLXD. Điều này dẫn đến việc khan hiếm nguồn VLXD trên thị trường,

\footnotetext{
"Tác giả liên hệ: htphuoc@ctu.edu.vn

Nhận ngày 20/05/2021, giải trình ngày 11/07/2021, chấp nhận đăng 10/08/2021
} 
đặc biệt là các loại vật liệu có nguồn gốc tự nhiên. Đáng kể là lượng xi măng tiêu thụ ngày càng lớn làm tăng hiệu ứng nhà kính và bầu không khí ngày càng ô nhiễm trầm trọng [1]. Thêm vào đó, vùng đồng bằng sông Cửu Long (ĐBSCL) là một trong những khu vực đang có lượng chất thải rất lớn từ các nhà máy nhiệt điện (như tro bay) so với các khu vực khác trong cả nước [2]. Chính vì thế, việc tìm ra các giải pháp để giải quyết các vấn đề nêu trên một cách có hiệu quả và bền vững là rất bức thiết.

Bên cạnh đó, theo báo cáo của Trương Duy Nghĩa [3], tổng nhu cầu than cho sản xuất điện của cả nước năm 2020 là khoảng 63 triệu tấn, năm 2025 sẽ là 95,4 triệu tấn và đến năm 2030 sẽ là 128,4 triệu tấn, tương ứng với tổng lượng tro thải ra là 15,09 triệu tấn (năm 2020), 17 triệu tấn (năm 2025) và 20,58 triệu tấn (năm 2030). Vì vậy, theo quyết định số 452/QĐ-TT của Thủ tướng Chính phủ [4] thì tro bay phù hợp với quy chuẩn quốc gia QCVN 16:2019/BXD [5] được coi là sản phẩm hàng hóa VLXD. Bên cạnh đó, TCVN 11586:2016 [6] cũng đã quy định chi tiết về xỉ hạt lò cao nghiền mịn dùng cho bê tông và vữa. Như vậy, có thể xem tro bay và xỉ lò cao là những nguồn vật liệu tiềm năng có thể sử dụng được trong các hoạt động xây dựng. Trên thế giới, đã có nhiều nghiên cứu về sử dụng phương pháp kiềm hoạt hóa để sản xuất vữa xây dựng và nhiều loại VLXD khác, trong đó sử dụng nhiều loại dung dịch kiềm khác nhau để kích hoạt phản ứng cho nhiều loại vật liệu từ nhiều nguồn khác nhau [7 - 10]. Riêng ở Việt Nam, cũng đã có một vài nghiên cứu về sử dụng phương pháp kiềm hoạt hóa hỗn hợp tro bay và xỉ lò cao kêt hợp với một số loại vật liệu khác để chế tạo nhiều dạng VLXD khác nhau như vữa, bê tông, gạch không nung, v.v. [11 - 14]. Tống Tôn Kiên [11] đã nghiên cứu khả năng tận dụng cát tái chế từ phế thải bê tông xi măng kết hợp với chất kết dính kiềm từ tro bay và xỉ lò cao để chế tạo vữa xây dựng không sử dụng xi măng. Kết quả cho thấy các hỗn hợp vữa chứa xỉ lò cao có cường độ 28 ngày cao hơn 2 đến 3 lần so với vữa sử dụng tro bay. Tác giả cũng khẳng định rằng hoàn toàn có thể chế tạo được các loại vữa xây dựng từ hỗn hợp cát tái chế và các loại vật liệu thay thế xi măng từ phế thải công nghiệp mà không cần sử dụng thêm xi măng Poóclăng. Loại vữa này hoàn toàn có thể thay thế vữa truyền thống dùng trong xây dựng. Bên cạnh đó, Phan Đức Hùng và Lê Anh Tuấn [12] đã chế tạo thành công bê tông geopolymer đạt giá trị cường độ chịu nén ở khoảng 26 đến $38 \mathrm{MPa}$, hoạt hóa từ tro bay bằng dung dịch kiềm gồm $\mathrm{NaOH}$ và $\mathrm{Na}_{2} \mathrm{SiO}_{3}$. Ngoài ra, các tác giả cũng cho biết việc bổ sung thêm khoảng 0,5\% sợi polypropylene giúp gia tăng cường độ và mô đun đàn hồi của bê tông. Trịnh Ngọc Duy [13] đã nghiên cứu tính chất cơ lý của vữa geopolymer để chế tạo gạch nhẹ. Ảnh hưởng của các tỷ lệ cát/tro bay, tỷ lệ dung dịch kiềm hoạt hóa/tro bay, tỷ lệ dung dịch $\mathrm{Na}_{2} \mathrm{SiO}_{3} / \mathrm{NaOH}$ và hàm lượng thể tích hạt xốp polystyrene đến cường độ chịu nén và khối lượng thể tích của vữa geopolymer và gạch nhẹ đã được tác giả nghiên cứu. Kết quả thực nghiệm cho thấy loại vữa geopolymer này có thể đạt cường độ nén cao nhất khoảng $8 \mathrm{MPa}$ và khối lượng thể tích nhỏ nhất khoảng $970 \mathrm{~kg} / \mathrm{m}^{3}$. Tỷ lệ cát/tro bay trong cấp phối tăng làm tăng cường độ chịu nén và khối lượng thể tích của vữa geopolymer. Tỷ lệ dung dịch kiềm hoạt hóa/tro bay bằng 0,6 cho kết quả tốt hơn, trong đó, tỷ lệ dung dịch $\mathrm{Na}_{2} \mathrm{SiO}_{3} / \mathrm{NaOH}$ bằng 2,5 tạo độ đặc chắc hơn cho vữa geopolymer nên khối lượng thể tích và cường độ chịu nén cao. Ngoài ra, hàm lượng hạt xốp polystyren sử dụng ảnh hưởng đáng kể đến cường độ chịu nén và khối lượng thể tích của vữa geopolymer. Gạch nhẹ sử dụng hạt xốp polystyren có thể sử dụng làm gạch xây tường bao che bên ngoài với ưu điểm nổi trội về tính nhẹ, khối lượng thể tích dưới $1300 \mathrm{~kg} / \mathrm{m}^{3}$ và cường độ nén trung bình là $5 \mathrm{MPa}$. Hơn nữa, Tống Tôn Kiên và cộng sự [14] đã nghiên cứu chế tạo vữa xây dựng và gạch xây không nung sử dụng chất kết dính kiềm hoạt hóa tro bay và xỉ lò cao. Kết quả nghiên cứu cho thấy chất lượng của các mẫu vữa và gạch không nung kiềm hoạt hóa tương đương với chất lượng của loại vữa và gạch sử dụng xi măng Poóclăng truyền thống.

Từ kết quả của các nghiên cứu trước, có thể thấy được tiềm năng sử dụng lượng tro bay và xỉ lò cao trong sản xuất chất kết dính thay thế xi măng ở Việt Nam là rất lớn. Với nguồn nguyên liệu dồi dào và nhu cầu sử dụng lớn, việc sản xuất vữa xây dựng từ hai nguồn chất thải, phụ phẩm này không những thúc đẩy nền kinh tế nước ta phát triển, mà còn đóng góp một phần quan trọng trong việc bảo vệ môi trường. Tuy vậy, thực tế cho thấy việc nghiên cứu sử dụng nguồn tro bay và xỉ lò cao trong nước để sản xuất VLXD nói chung và vữa xây dựng nói riêng còn hạn chế, nhất là ứng dụng phương pháp kiềm hoạt hóa. Chính vì vậy, nghiên cứu tận dụng nguồn tro bay (từ nhà máy nhiệt điện Duyên Hải, Trà Vinh) và xỉ lò cao nghiền mịn (từ các nhà máy luyện kim thuộc tập đoàn Hòa Phát, Hưng Yên) trong chế tạo vữa xây dựng bằng phương pháp kiềm hoạt hóa (sử dụng dung dịch kiềm gồm $\mathrm{NaOH}$ và $\mathrm{Na}_{2} \mathrm{SiO}_{3}$ ) với định hướng ứng dụng cho hoạt động xây tô hoàn thiện công trình là cần thiết. Theo đó, các mẫu vữa được thiết kế với mác yêu cầu tối thiểu M10. Ảnh hưởng của các tỉ lệ xỉ lò cao/tro bay (theo khối lượng) và các nồng độ khác nhau của dung dịch $\mathrm{NaOH}$. Các đặc tính kỹ thuật của các mẫu vữa được đánh giá gồm, cường độ chịu nén, độ hút nước, độ co khô, tốc độ truyền sóng siêu âm qua mẫu và phân tích đặc điểm vi cấu trúc vữa trên cơ sở đối sánh với các tính chất tương ứng của mẫu vữa xi măng thông thường.

\section{Vật liệu và phương pháp thí nghiệm \\ 2.1 . Vật liệu và cấp phối}

Trong nghiên cứu này, xi măng (loại PCB40 của công ty xi măng Insee), tro bay (loại $\mathrm{F}$ của nhà máy nhiệt điện Duyên Hải) và xỉ 
lò cao nghiền mịn (loại S95 của tập đoàn Hòa Phát) được dùng như thành phần chất kết dính. Khối lượng riêng và thành phần hóa học chính của ba loại vật liệu này được trình bày ở Bảng 1 . Bên cạnh đó, cát sông tự nhiên (khối lượng riêng 2,69 g/ $\mathrm{cm}^{3}$, độ hút nước 1,12\% và mô đun độ lớn 1,47 ) được dùng như thành phần cốt liệu nhỏ trong cấp phối vữa.

\section{Bảng 1.}

Khối lượng riêng và thành phần hóa học của xi măng, tro bay và xỉ lò cao.

\begin{tabular}{|c|c|c|c|c|c|c|c|}
\hline \multirow{2}{*}{ Vật liệu } & Khối lượng & \multicolumn{5}{|c|}{ Thành phà̀n hóa học (\% theo khối lượng) } \\
\cline { 3 - 8 } & riêng $\left(\mathrm{g} / \mathrm{cm}^{3}\right)$ & $\mathrm{SiO}_{2}$ & $\mathrm{Fe}_{2} \mathrm{O}_{3}$ & $\mathrm{Al}_{2} \mathrm{O}_{3}$ & $\mathrm{CaO}$ & $\mathrm{MgO}$ & Khác \\
\hline Xi măng & 2,84 & 23,5 & 3,7 & 6,0 & 59,9 & 2,0 & 5,0 \\
\hline Tro bay & 2,14 & 59,2 & 6,1 & 26,7 & 1,1 & 0,9 & 6,1 \\
\hline Xỉ lò cao & 2,85 & 35,9 & 0,3 & 13,0 & 38,1 & 8,0 & 4,7 \\
\hline
\end{tabular}

\section{Bảng 2.}

Các tính chất của dung dịch kiềm hoạt hóa và phụ gia siêu dẻo.

\begin{tabular}{|c|c|c|}
\hline Vật liệu & $\begin{array}{c}\text { Trọng lượng } \\
\text { riêng }\left(\mathrm{g} / \mathrm{cm}^{3}\right)\end{array}$ & \multicolumn{1}{c|}{ Ghi chú } \\
\hline $\mathrm{NaOH}$ & 1,22 & $\begin{array}{l}\text { Tự pha chế theo nồng độ mong muốn từ } \\
\mathrm{NaOH} \text { rắn dạng vảy, độ tinh khiết } 98 \%\end{array}$ \\
\hline $\mathrm{Na}_{2} \mathrm{SiO}_{3}$ & 1,38 & $\begin{array}{l}\text { Mua thương phẩm (hàm lượng } \mathrm{SiO}_{2}= \\
\left.25,72 \%, \mathrm{Na}_{2} \mathrm{O}=8,63 \%\right)\end{array}$ \\
\hline $\begin{array}{c}\text { Phụ gia } \\
\text { siêu dẻo }\end{array}$ & 1,15 & $\begin{array}{l}\text { Gốc polycarboxylate, loại } \mathrm{G}, \text { mua thương } \\
\text { phẩm (dạng dung dịch, có độ } \mathrm{pH}=5)\end{array}$ \\
\hline
\end{tabular}

\section{Bảng 3.}

Cấp phối vật liệu dùng để chế tạo mẫu vữa xây dựng không xi măng.

\begin{tabular}{|c|c|c|c|c|c|c|c|}
\hline \multirow{2}{*}{$\begin{array}{l}\text { Kí hiệu } \\
\text { cấp phối }\end{array}$} & \multicolumn{7}{|c|}{ Thành phần vật liệu (đơn vị: kg) } \\
\hline & $\begin{array}{c}\text { Xỉ lò } \\
\text { cao }\end{array}$ & $\begin{array}{l}\text { Tro } \\
\text { bay }\end{array}$ & $\mathrm{NaOH}$ & $\mathrm{Na}_{2} \mathrm{SiO}_{3}$ & Nước & $\begin{array}{l}\text { Cát } \\
\text { sông }\end{array}$ & $\begin{array}{l}\text { Phụ gia } \\
\text { siêu dẻo }\end{array}$ \\
\hline S3F7N10 & 109,4 & 255,3 & 88,2 & 55,0 & 206,8 & 1433,1 & 8,0 \\
\hline S5F5N10 & 182,2 & 182,2 & 88,1 & 54,9 & 206,6 & 1431,8 & 8,0 \\
\hline S7F3N10 & 251,0 & 107,6 & 86,7 & 54,1 & 203,3 & 1409,0 & 8,0 \\
\hline S5F5N6 & 180,8 & 180,8 & 87,5 & 54,5 & 205,1 & 1421,1 & 7,9 \\
\hline S5F5N8 & 182,2 & 182,2 & 88,1 & 54,9 & 206,6 & 1431,8 & 8,0 \\
\hline S5F5N14 & 182,2 & 182,2 & 88,1 & 54,9 & 206,6 & 1431,8 & 8,0 \\
\hline C100 & & Xi măn & $=46^{\prime}$ & & 373,8 & 1224,3 & 6,8 \\
\hline
\end{tabular}

Nghiên cứu này sử dụng hỗn hợp dung dịch $\mathrm{NaOH}$ và $\mathrm{Na}_{2} \mathrm{SiO}_{3}$ (với các tính chất như trình bày ở Bảng 2 ) làm dung dịch kiềm hoạt hóa. Dung dịch kiềm hoạt hóa được đặc trưng bởi môđun kiềm và hàm lượng kiềm trong chất kết dính được gọi là hàm lượng kiềm tương đương. Trong đó, môđun kiềm $(\mathrm{Ms})=$ tỉ lệ mole của $\mathrm{SiO}_{2} / \mathrm{Na}_{2} \mathrm{O}$ và hàm lượng kiềm tương đương $(\mathrm{AE})=$ tỉ lệ khối lượng của $\mathrm{Na}_{2} \mathrm{O}$ /tổng khối lượng tro bay và xỉ lò cao sử dụng. Ngoài ra, tỷ lệ nước/(tro bay và xỉ lò cao) được dùng để điều chỉnh nồng độ của dung dịch kiềm hoạt hóa. Lưu ý rằng, lượng nước được sử dụng sẽ bao gồm cả lượng nước trộn và lượng nước có sẵn trong dung dịch $\mathrm{NaOH}$ và $\mathrm{Na}_{2} \mathrm{SiO}_{3}$. Hàm lượng cát tự nhiên được xác định dựa trên cơ sở tham khảo định mức nhà nước cho loại vữa xây tô mác M10 và điều chỉnh cho phù hợp với loại vật liệu sử dụng trong nghiên cứu. Theo đó, tỷ lệ cát/(tro bay và xỉ lò cao) là 3,93 . Ngoài ra, hàm lượng phụ gia siêu dẻo cũng được điều chỉnh để đảm bảo hỗn hợp vữa tươi có độ chảy xòe trong khoảng khống chế là $170 \pm 5 \mathrm{~mm}$ để cho vữa có khả năng làm việc tốt và có thể dễ dàng so sánh, đánh giá các tính chất kỹ thuật giữa các cấp phối vữa với nhau. Kết quả tính toán thành phần cấp phối vật liệu cho mỗi mét khối vữa được trình bày chi tiết ở Bảng 3 .

Giải thích ký hiệu cấp phối: Hai kí tự đầu (S3, S5, S7) tương ứng với hàm lượng xỉ lò cao là $30 \%, 50 \%$ và $70 \%$ so với tổng khối lượng (tro bay + xỉ lò cao); Hai kí tự tiếp theo (F3, F5, F7) tương ứng với hàm lượng tro bay là $30 \%, 50 \%$ và $70 \%$ so với tổng khối lượng (tro bay + xỉ lò cao); Các kí tự còn lại (N6, N8, N10, N14) tương ứng với nồng độ $\mathrm{NaOH}$ sử dụng ở $6 \mathrm{M}, 8 \mathrm{M}, 10 \mathrm{M}$ và $14 \mathrm{M}$; Riêng $\mathrm{C} 100$ là cấp phối sử dụng 100 \% xi măng (làm cấp phối đối chứng).

\subsection{Phương pháp thí nghiệm}

\subsubsection{Chuẩn bị mẫu thí nghiệm}

Bước 1: Các chất kết dính sau khi cân theo cấp phối đã định trước sẽ được trộn khô trong máy trộn khoảng 1 phút, sau đó từ từ cho hỗn hợp dung dịch kiềm (gồm $\mathrm{NaOH}$ và $\mathrm{Na}_{2} \mathrm{SiO}_{3}$ đã được trộn đều với nhau trước) vào máy trộn. Tiếp tục trộn ở tốc độ vừa trong khoảng thời gian 3 phút.

Bước 2: Cho toàn bộ lượng cát vào máy trộn, đồng thời từ từ cho hỗn hợp nước và phụ gia siêu dẻo (đã được trộn đều với nhau trước) vào máy trộn đều trong khoảng 2 phút đến khi thu được hỗn hợp vữa đồng nhất.

Bước 3: Rót hỗn hợp vữa đồng nhất vào khuôn với các hình dạng và kích thước khác nhau để chuẩn bị mẫu cho các thí nghiệm khác nhau. Cụ thể là, mẫu lăng trụ có kích thước $(40 \times 40 \times 160)$ mm được chế tạo cho thí nghiệm xác định cường độ chịu nén, mẫu lập phương $(50 \times 50 \times 50) \mathrm{mm}$ được chế tạo cho thí nghiệm xác định độ hút nước, mẫu lăng trụ có kích thước $(25 \times 25 \times 285) \mathrm{mm}$ 
được chế tạo cho thí nghiệm xác định độ co khô và mẫu trụ đường kính $100 \mathrm{~mm}$, chiều cao $200 \mathrm{~mm}$ được chế tạo cho thí nghiệm xác định tốc độ truyền sóng siêu âm qua mẫu.

Bước 4: Các mẫu sau khi được cho vào khuôn thì được đặt ở trong phòng thí nghiệm, sau 24 giờ thì tiến hành tháo khuôn và bảo dưỡng các mẫu ở điều kiện phòng thí nghiệm cho đến tuổi thí nghiệm theo kế hoạch.

\subsubsection{Phương pháp thí nghiệm}

Cường độ chịu nén và độ co khô của các mẫu vữa được xác định ở các ngày tuổi $1,3,7,14$ và 28 theo chỉ dẫn của TCVN 312111:2003 [15] và TCVN 8824:2011 [16] tương ứng. Bên cạnh đó, các giá trị về độ hút nước và tốc độ truyền sóng siêu âm qua mẫu được ghi nhận ở các mẫu 28 ngày tuổi theo chỉ dẫn của TCVN 312118:2003 [17] và TCVN 9357:2012 [18] tương ứng. Ngoài ra, hình ảnh vi cấu trúc của các mẫu vữa ở 28 ngày cũng được quan sát dưới kính hiển vi điện từ quét (SEM).

\section{Kết quả nghiên cứu}

\subsection{Cường độ chịu nén}

Các mẫu vữa S5F5N6, S5F5N8 và S3F7N10 có sự phát triển cường độ theo thời gian bảo dưỡng hầu như không đáng kể (Hình 1). Do đó, kết quả xác định cường độ chịu nén của các mẫu vữa này sẽ không trình bày ở đây. Sự phát triển cường độ chịu nén của các mẫu vữa còn lại trong nghiên cứu này đã được xác định và trình bày ở Hình 2.

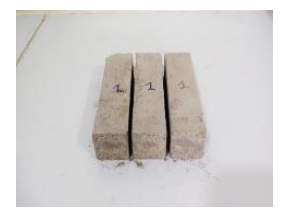

(a) S5F5N6

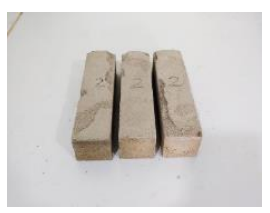

(b) $\mathrm{S} 5 \mathrm{~F} 5 \mathrm{~N} 8$

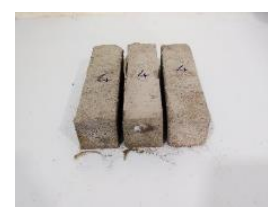

(c) S3F7N10
Hình 1. Các mẫu vữa hầu như không phát triển cường độ.

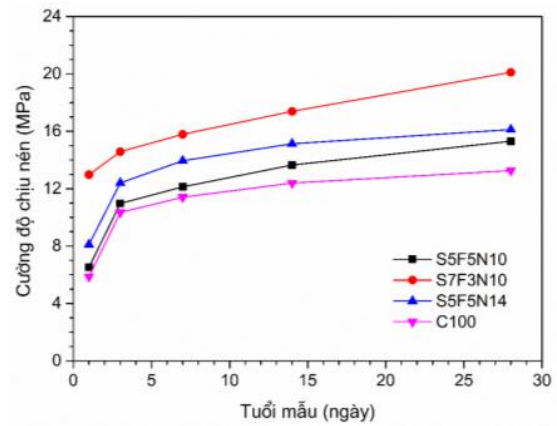

Hình 2. Sự phát triển cường độ chịu nén của các mẫu vữa.
Nhìn chung, giá trị cường độ chịu nén của các mẫu vữa tăng liên tục theo thời gian bảo dưỡng. Đặc biệt, giá trị cường độ chịu nén tăng khá nhanh trong ba ngày đầu sau khi chế tạo mẫu, cường độ vẫn tiếp tục phát triển ở các ngày tiếp theo nhưng với tốc độ tăng chậm hơn. Ở 28 ngày tuổi, các giá trị của cường độ chịu nén của các cấp phối S5F5N10, S7F3N10, S5F5N14 và C100 lần lượt là 15,31 MPa, 20,11 MPa, 16,12 MPa và 13,26 MPa. Như vậy, các cấp phối vữa kiềm hoạt hóa đều có giá trị cường độ chịu nén cao hơn so với cường độ của mẫu vữa chỉ sử dụng xi măng. Trong đó, mẫu vữa S7F3N10 được chế tạo từ $70 \%$ xỉ lò cao và $30 \%$ tro bay với nồng độ $\mathrm{NaOH}$ là $10 \mathrm{M}$ có giá trị cường độ chịu nén cao nhất so với các mẫu vữa khác trong nghiên cứu. Như vậy, có thể thây rằng khi tăng hàm lượng xỉ lò cao (giảm hàm lượng tro bay tương ứng) thì cường độ chịu nén cũng tăng. Hiện tượng này có thể giải thích là do xỉ lò cao chứa thành phần $\mathrm{CaO}$ và $\mathrm{SiO}_{2}$ tương đối cao (xem ở Bảng 1 ), do đó khi tăng hàm lượng xỉ lò cao thì hàm lượng $\mathrm{CaO}$ và $\mathrm{SiO}_{2}$ trong cấp phối cũng tăng cao tương ứng. Khi đó, thành phần $\mathrm{CaO}$ và $\mathrm{SiO}_{2}$ vô định hình trong xỉ lò cao sẽ hòa tan tốt trong môi trường có kích thích kiềm, thúc đẩy các phản ứng hóa học để hình thành các tinh thể gel C-S-H, góp phần làm tăng cường độ của các mẫu vữa [19]. Ngoài ra, khi hàm lượng xỉ lò cao tham gia trong phản ứng tạo ra một lượng gel C-S-H lớn bao quanh các hạt cốt liệu để gắn kết chúng với nhau làm cho thể tích lỗ rỗng của hỗn hợp giảm xuống, cấu trúc mẫu trở nên đặc chắc hơn (xem Hình 8 ), chính điều này đã làm tăng vượt trội cường độ chịu nén của mẫu S7F3N10 so với các mẫu còn lại [20]. Một nguyên nhân khác là kích thước hạt của xỉ lò cao mịn hơn so với các loại vật liệu khác trong hỗn hợp nên diện tích bề mặt lớn và khả năng thấm hút dung dịch kiềm hoạt hóa nhiều hơn, mức độ tham gia phản ứng hóa học cũng sẽ cao hơn so với tro bay [21]. Hơn nữa, khi thành phần hạt mịn thì khả năng len lõi vào cốt liệu giúp lắp đầy các lỗ rỗng và lèn chặt và cốt liệu cũng tốt hơn, giúp mẫu vữa trở nên đặc chắc hơn [22]. Mặc khác, khi giữ nguyên hàm lượng xỉ lò cao và tro bay, chỉ tăng nồng độ $\mathrm{NaOH}$ từ 10M ở cấp phối S5F5N10 lên 14M ở cấp phối S5F5N14 thì cường độ chịu nén cũng có xu hướng tăng. Như vậy, tăng nồng độ dung dịch $\mathrm{NaOH}$ cũng góp phần cho tích cực phản ứng tạo gel C-S-H, làm cho cấu trúc mẫu đặc chắc hơn [23, 24]. Tuy nhiên, khi so sánh giữa cấp phối S5F5N14 với cấp phối S7F3N10 ta thấy mẫu S5F5N14 có cường độ chịu nén thâp hơn mẫu S7F3N10. Điều này chứng tỏ việc phối trộn thành phần chất kết dính một cách hợp lý sẽ góp phần tăng cường độ và mang lại hiệu quả kinh tế khi sử dụng ít $\mathrm{NaOH}$ và tiêu thụ nhiều lượng phụ phẩm tro xỉ. Trong nghiên cứu này, mẫu S5F5N10 được xem là mẫu phù hợp cho sản xuất vữa xây dựng. Cấp phối này cho kết quả cường độ chịu nén ở 28 ngày đạt 15,31 MPa, đạt yêu cầu thiết kế vữa xây dựng với mác tối thiểu M10 theo tiêu chuẩn TCVN 4314:2003 [25]. 


\section{2. Đô hút nước}

Trong quá trình thực hiện thí nghiệm nhận thấy các mẫu vữa S3F7N10, S5F5N6 và S5F5N8 có cường độ hầu như không phát triển và các mẫu này bị vỡ ra khi ngâm trong nước (Hình 3), nên kết quả xác định độ hút nước cho các mẫu này không được trình bày ở đây. Độ hút nước của các mẫu vữa còn lại trong nghiên cứu được xác định và trình bày trong Hình 4.

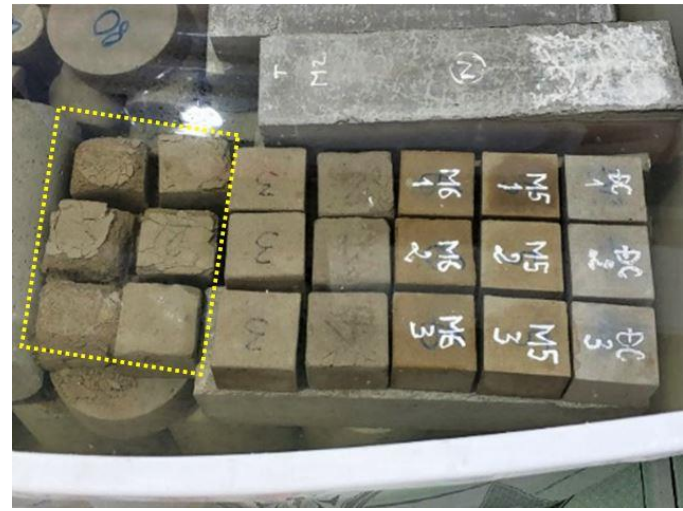

Hình 3. Các mẫu vữa S3F7N10, S5F5N6 và S5F5N8 bị vỡ khi ngâm trong nước.

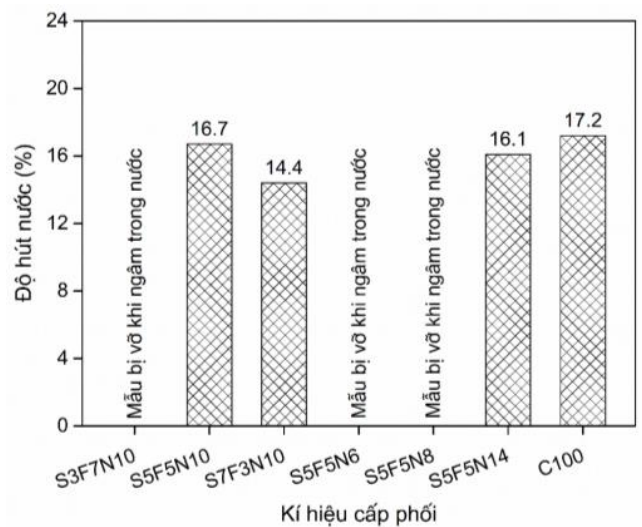

Hình 4. Độ hút nước của các mẫu vữa ở 28 ngày.

Đối với các mẫu vữa có cùng hàm lượng tro bay 50 \% và xỉ lò cao $50 \%$, khi tăng nồng độ $\mathrm{NaOH}$ thì độ hút nước có xu hướng giảm nhẹ. Cụ thể là, mẫu vữa S5F5N10 có độ hút nước là 16,7 \%. Giá trị này giảm nhẹ xuống còn 16,1 \% ở cấp phối S5F5N14. Kết quả này có thể là do mức độ tham gia phản ứng hóa học cũng như tốc độ của các phản ứng này diễn ra tốt hơn trong môi trường kiềm có nồng độ cao hơn, dẫn đến kết quả tạo ra các sản phẩm sau phản ứng nhiều hơn (chủ yếu là gel C-S-H), giúp cấu trúc mẫu vữa trở nên đặc chắc hơn và từ đó giảm khả năng hút nước $[23,26]$. Đối với các mẫu vữa sử dụng cùng nồng độ $\mathrm{NaOH}$ là $10 \mathrm{M}$, mẫu vữa chứa hàm lượng xỉ lò cao nhiều hơn sẽ có độ hút nước thấp hơn. Cụ thể là ở mẫu S7F3N10 thì độ hút nước ghi nhận được là 14,4 \%, thấp hơn nhiều so với mẫu S5F5N10 (16,7 \%). Như đã trình bày ở trên, hiện tượng giảm khả năng hút nước của mẫu vữa khi tăng hàm lượng xỉ lò cao là do sự gia tăng hàm lượng $\mathrm{CaO}$ và tăng lượng sản phẩm sau phản ứng (gel C-S-H) $[19,20]$ cũng như tăng mức độ phản ứng và hiệu ứng lèn chặt $[21,22]$ giúp mẫu trở nên chắc chắc hơn với ít lỗ rỗng hơn (xem Hình 8) và từ đó độ hút nước cũng thấp hơn. Kết quả thí nghiệm còn cho thấy tất cả các mẫu vữa được chế tạo bằng phương pháp kiềm hoạt hóa để có giá trị độ hút nước thấp hơn so với mẫu đối chứng C100 (17,2%).

\section{3. Đô co khô}

Sự thay đổi chiều dài các mẫu vữa ở 28 ngày tuổi được ghi nhận và trình bày ở Hình 5 . Với cùng hàm lượng tro bay 50 \% và xỉ lò cao $50 \%$, mức độ thay đổi chiều dài của mẫu vữa sử dụng $\mathrm{NaOH} 14 \mathrm{M}$ (S5F5N14) và $\mathrm{NaOH} 10 \mathrm{M}$ (S5F5N10) ở 28 ngày tuổi lần lượt là $0,164 \%$ và $-0,174 \%$. Bên cạnh đó, giá trị thay đổi chiều dài được ghi nhận ở mẫu chứa ít xỉ lò cao (S5F5N10) và ở mẫu chứa nhiều xỉ lò cao (S7F3N10) lần lượt là $-0,174 \%$ và $-0,140 \%$. Như đề cập ở trên, tro bay có thành phần hạt lớn hơn so với xi măng và xỉ lò cao nên khi tăng hàm lượng tro bay trong hỗn hợp thì hiệu ứng lèn chặt không phát huy đáng kể. Thêm vào đó, mức độ tham gia phản ứng hóa học của tro bay cũng hạn chế hơn so với xỉ lò cao [21]. Như vậy, mẫu chứa nhiều tro bay có cấu trúc lỗ rỗng nhiều hơn so với mẫu chứa nhiều xỉ lò cao (điều này được chứng minh ở Hình 8), dẫn đến khả năng co khô của các mẫu vữa chứa nhiều tro bay cũng có xu hướng cao hơn so với các mẫu vữa chứa nhiều xỉ lò cao [27]. So với mẫu đối chứng C100 có độ co khô ghi nhận được là $-0,309 \%$ thì các mẫu vữa không sử dụng xi măng có mức độ thay đổi chiều dài nhỏ hơn đáng kể. Có thể giải thích hiện tượng này là do phản ứng kiềm hoạt hóa hỗn hợp tro bay và xỉ lò cao ít sinh nhiệt hơn so với phản ứng thủy hóa của xi măng làm cho các mẫu vữa không xi măng có độ biến dạng thể tích thấp và ít co khô hơn [28].

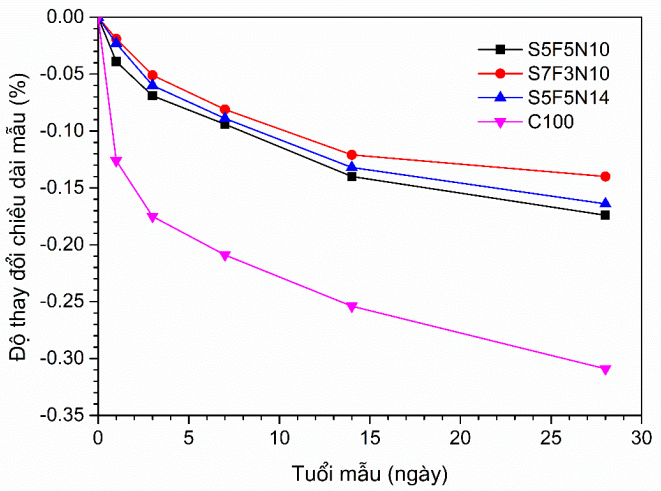

Hình 5. Độ co khô của các mẫu vữa quan sát đến 28 ngày. 


\subsection{Tốc độ truyền sóng siêu âm qua mẫu}

Tốc độ truyền sóng siêu âm qua các mẫu vữa ở 28 ngày tuổi được ghi nhận và trình bày ở Hình 6 . Tốc độ truyền sóng siêu âm qua mẫu tăng khi tăng hàm lượng xỉ lò cao, giá trị được ghi nhận từ 2749 $\mathrm{m} / \mathrm{s}$ (mẫu dùng $50 \%$ xỉ lò cao) tăng lên $3142 \mathrm{~m} / \mathrm{s}$ (mẫu dùng $70 \%$ xỉ lò cao). Mặt khác, với 2 mẫu có cùng hàm lượng tro bay và xỉ lò cao, giá trị vận tốc truyền sóng siêu âm qua mẫu dùng $\mathrm{NaOH} 14 \mathrm{M}$ (S5F5N14) tăng 6,07 \% so với mẫu dùng $\mathrm{NaOH}$ 10M (S5F5N10). Kết quả thí nghiệm cho thấy rằng tốc độ truyền sóng siêu âm qua các mẫu vữa không sử dụng xi măng lần lượt cao hơn 21,19 \% (mẫu S5F5N10), 24,26 \% (mẫu S5F5N14) và 30,59 \% (mẫu S7F3N10) so với mẫu đối chứng C100 (chỉ 2406 m/s). Tốc độ truyền sóng siêu âm qua các mẫu vữa không sử dụng xi măng cao hơn đáng kể so với mẫu đối chứng chứng tỏ các mẫu vữa không xi măng có độ đồng nhất cao và đặc chắc hơn. Giá trị tốc độ truyền sóng siêu âm qua mẫu cũng phù hợp với kết quả xác định độ hút nước (Hình 4) và cường độ chịu nén (Hình 2) của các mẫu vữa. Có thể nhận định rằng, mẫu vữa có độ đặc chắc và độ đồng nhất cao thường sẽ có ít lỗ rỗng nên độ hút nước sẽ thấp và đương nhiên cường độ chịu nén cũng sẽ cao, như vậy tốc độ truyền sóng siêu âm qua mẫu cũng sẽ cao tương ứng. Mối tương quan giữa tốc độ truyền sóng siêu âm và cường độ chịu nén của các mẫu vữa ở 28 ngày tuổi (Hình 7) cũng thể hiện rõ nhận định này. Kết quả ở Hình 6 cho thấy giá trị tốc độ truyền sóng siêu âm qua bốn mẫu vữa đều nằm trong khoảng $2000 \mathrm{~m} / \mathrm{s}$ đến $3000 \mathrm{~m} / \mathrm{s}$ (riêng cấp phối S7F3N10 có giá trị tốc độ truyền sóng siêu âm lớn hơn 3000 m/s một chút), nên các loại vữa kiềm hoạt hóa được chế tạo trong nghiên cứu này được xếp loại vữa có chất lượng thấp theo phân loại của Hassiba và cộng sự [29]. Kết quả này cũng phù hợp với vữa mác thấp ( $\geq 10$ $\mathrm{MPa})$ được thiết kế cho mục đích xây tô hoàn thiện thông thường.

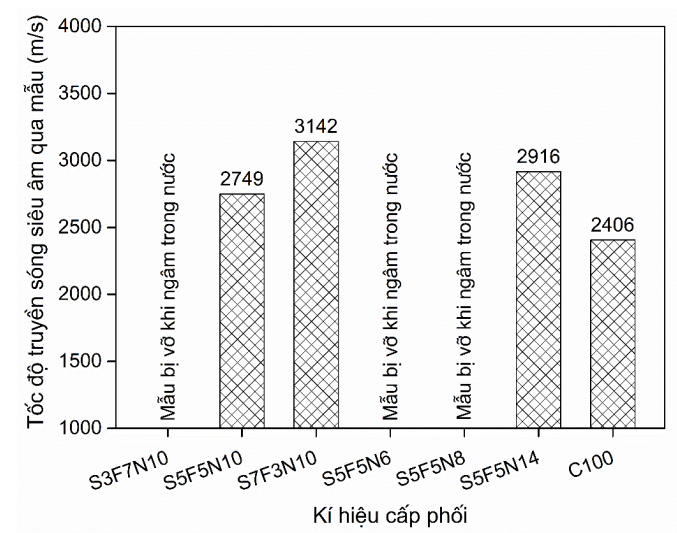

Hình 6. Tốc độ truyền sóng siêu âm qua các mẫu vữa ở 28 ngày tuổi.

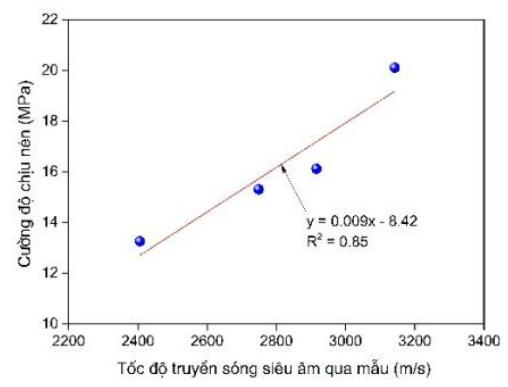

Hình 7. Mối tương quan giữa tốc độ truyền sóng siêu âm và cường độ chịu nén của các mẫu vữa ở 28 ngày tuổi.

\subsection{Phân tích vi cấu trúc}

Hình ảnh SEM của các mẫu vữa ở 28 ngày tuổi được trình bày ở Hình 8. Từ hình ảnh này cũng có thể dự đoán mức độ phản ứng hóa học diễn ra trong các mẫu vữa được chế tạo với các hàm lượng khác nhau của xỉ lò cao và các nồng độ khác nhau của dung dịch $\mathrm{NaOH}$ được sử dụng. Có thể thấy rằng, mẫu vữa sử dụng dung dịch $\mathrm{NaOH}$ $10 \mathrm{M}$ kêt hợp với $\mathrm{Na}_{2} \mathrm{SiO}_{3}$ làm dung dịch kiềm hoạt hóa hỗn hợp $70 \%$ xỉ lò cao và $30 \%$ tro bay (mẫu S7F3N10, Hình $8 \mathrm{~b}$ ) có cấu trúc đặc chắc nhất so với các mẫu còn lại. Quan sát này cũng hoàn toàn phù hợp với kết quả thí nghiệm về cường độ chịu nén, độ hút nước và độ co khô của mẫu vữa như đã trình bày ở các phần trên. Từ kết quả này có thể nhận định rằng, các tính chất kỹ thuật và vi cấu trúc của các mẫu vữa được cải thiện đáng kể khi tăng hàm lượng xỉ lò cao trong cấp phối hoặc tăng nồng độ dung dịch kiềm hoạt hóa. Trong đó, tăng hàm lượng xỉ lò cao có tác dụng rõ rệt hơn và mang lại hiệu quả hơn về mặt kinh tế và môi trường khi hàm lượng tro xỉ được tận dụng nhiều hơn và lượng hóa chất được sử dụng ít hơn.

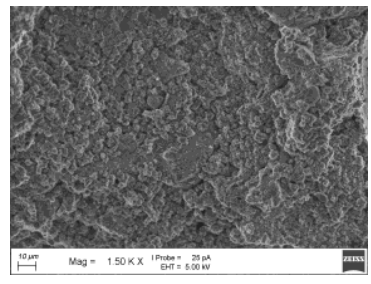

(a) $\mathrm{S} 5 \mathrm{~F} 5 \mathrm{~N} 10$

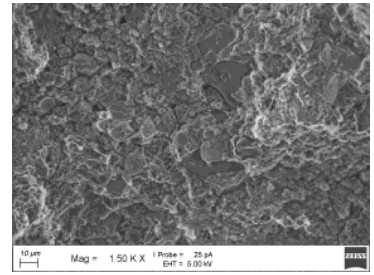

(c) S5F5N14

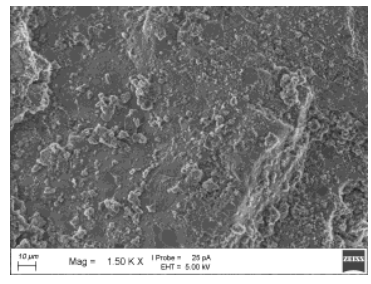

(b) S7F3N10

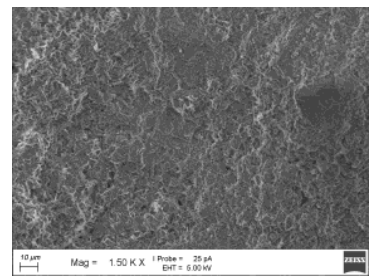

(d) $\mathrm{C} 100$
Hình 8. Hình ảnh SEM của các mẫu vữa 28 ngày tuổi ở cùng độ phóng đại $\times 1500$. 


\section{Kết luận}

Nghiên cứu tận dụng nguồn tro bay và xỉ lò cao nghiền mịn từ các nhà máy nhiệt điện và luyện kim ở Việt Nam trong chế tạo vữa xây dựng bằng phương pháp kiềm hoạt hóa với định hướng ứng dụng cho hoạt động xây tô hoàn thiện công trình đã được thực hiện. Dựa trên kết quả thí nghiệm thu được, có thể đưa ra một số kết luận chủ yếu như sau:

Mẫu vữa kiềm hoạt hóa không xi măng có cường độ chịu nén ở 28 ngày dao động từ 15,31 MPa đến 20,11 MPa, cao hơn cấp phối đối chứng sử dụng $100 \%$ xi măng (chỉ 13,26 MPa). Các mẫu vữa sử dụng $70 \%$ tro bay và các mẫu vữa được hoạt hóa bằng dung dịch kiềm có sử dụng $\mathrm{NaOH}$ ở nồng độ $6 \mathrm{M}$ đến $8 \mathrm{M}$ hầu như không phát triển cường độ trong suốt quá trình bảo dưỡng.

Việc tăng hàm lượng xỉ lò cao hay tăng nồng độ dung dịch $\mathrm{NaOH}$ trong cấp phối làm giảm độ hút nước, giảm độ co khô và tăng tốc độ truyền sóng siêu âm qua các mẫu vữa. Độ hút nước, mức độ thay đổi chiều dài và tốc độ truyền sóng siêu âm của các mẫu vữa kiềm hoạt hóa ở 28 ngày tuổi dao động tương ứng ở các khoảng 14,4 $\%$ đến $16,7 \%,-0,140 \%--0,174 \%$ và $2749-3142 \mathrm{~m} / \mathrm{s}$. Trong đó, mẫu vữa S7F3N10 có giá trị độ hút nước và mức độ thay đổi chiều dài thấp nhất, trong khi giá trị tốc độ truyền sóng siêu âm là cao nhất trong số các cấp phối vữa, vượt trội hơn cả mẫu vữa xi măng đối chứng.

Trong số các mẫu vữa kiềm hoạt hóa được chuẩn bị trong nghiên cứu này thì mẫu S5F5N10 có cường độ chịu nén 15,31 MPa, thỏa mãn yêu cầu về cường độ thiết kế ( $\geq 10 \mathrm{MPa}$ ở 28 ngày) và sử dụng hàm lượng tro bay cao đến 50 \%. Các tính chất kỹ thuật khác của cấp phối này cũng phù hợp cho định hướng ứng dụng trong hoạt động xây tô hoàn thiện công trình. Hình ảnh SEM cũng cho thấy mẫu này có cấu trúc đặc chắc hơn. Do đó, đây được xem là cấp phối phù hợp để sản xuất và ứng dụng trong thực tế.

Quan sát các biểu hiện của mẫu vữa ở các độ tuổi dài ngày hơn cần được thực hiện trong các nghiên cứu tiếp theo để có cái nhìn tổng quát hơn về sự phát triển ở các tính chất của mẫu vữa. Ngoài ra, một số thí nghiệm chuyên sâu hơn về phân tích sản phẩm sau phản ứng (ví dụ như XRD, FTIR, EDS, v.v.) cũng cần được thực hiện ở các nghiên cứu sau để nắm rõ cơ chế của các phản ứng và có thể giải thích chi tiết về sự phát triển các đặc điểm cơ học của mẫu vữa kiềm hoạt hóa không xi măng.

\section{Tài liệu tham khảo}

[1]. Nguyễn Ái Dương. "Giải pháp giảm nhẹ phát thải khí nhà kính trong lĩnh vực sản xuất xi măng hướng đến sự phát triển bền vững," Tạp chí Môi trường, số Chuyên đề Tăng trưởng xanh năm 2018.
[2]. Báo điện tử Vietnamnet. "Núi tro, xỉ 13 triệu tấn đe dọa đồng bằng sông Cửu Long," Truy cập ngày 28/04/2021.

[3]. Cổng thông tin điện tử Bộ Công thương. "Tạo điều kiện cho các doanh nghiệp trong lĩnh vực sản xuất vật liệu xây dựng từ tro xỉ," Truy cập ngày $28 / 04 / 2021$.

[4]. Quyết định số 452/QĐ-TTg . "Phê duyệt Đề án đẩy mạnh xử lý, sử dụng tro, xỉ, thạch cao của các nhà máy nhiệt điện, nhà máy hóa chất, phân bón làm nguyên liệu sản xuất vật liệu xây dựng và trong các công trình xây dựng,", ngày 12 tháng 04 năm 2017, Việt Nam.

[5]. QCVN 16:2019/BXD. "Quy chuẩn kỹ thuật quốc gia về sản phẩm, hàng hóa vật liệu xây dựng," Quy chuẩn quốc gia Việt Nam, 2019.

[6]. TCVN 11586. "Xỉ hạt lò cao nghiền mịn dùng cho bê tông và vữa,' Tiêu chuẩn Việt Nam, 2016.

[7]. J. L. Provis. "Alkali-activated materials," Cement and Concrete Research, Vol.114, pp. 40-48, Dec.2018, DOI.10.1016/j.cemconres.2017.02.009

[8]. P. T.Fernando , C. G.João , J.Said. "Alkali-activated binders: A review. Part 1. Historical background, terminology, reaction mechanisms and hydration products," Construction and Building Materials , Vol.22, pp. 1305-1314, Jul.2008, DOI. 10.1016/j.conbuildmat.2007.10.015.

[9]. F. J.Ana , C.Nuno , M.Tiago , P.Ángel. "Sustainable alkali activated materials: Precursor and activator derived from industrial wastes," Journal of Cleaner Production, Vol.162, pp. 1200-1209, Sep.2017, DOI. 10.1016/j.jclepro.2017.06.151

[10]. P. O.Awoyera , A.Adesina , A.Sivakrishna , R.Gobinath , K. R.Kumar , A.Srinivas. "Alkali activated binders: Challenges and opportunities," Materials Today: Proceedings, Vol.27, pp. 40-43, 2020.

[11]. Tống Tôn Kiên. , Nghiên cứu khảo sát khả năng tận dụng cát tái chế từ phế thải bê tông để chế tạo vữa xây dựng không sử dụng xi măng, Tạp chí Vật liệu Xây dựng, số 6, tr. 64-69, 2014.

[12]. Phan Đức Hùng, Lê Anh Tuấn. "Tính chất cơ học của bê tông geopolymer sử dụng tro bay gia cường sợi poly-propylene," Tạp chí Khoa học Công nghệ Xây dựng, số 1, tr. 60-67, 2016.

[13]. Trịnh Ngọc Duy. "Nghiên cứu tính chất cơ lý của vữa geopolymer để chế tạo gạch nhẹ," Luận văn Thạc sĩ ngành Kỹ thuật xây dựng công trình dân dụng và công nghiệp, Trường Đại học Sư phạm Kỹ thuật thành phố Hồ Chi Minh, 2016.

[14]. Tống Tôn Kiên, Nguyễn Mạnh Phát, Phạm Hữu Hanh, Lưu Văn Sáng. "Nghiên cứu chế tạo gạch không nung và vữa từ phế thải công nghiệp phục vụ phát triển bền vững," Tạp chí Khoa học Công nghệ Xây dựng, số 1 , tr. 3-10, 2014

[15]. TCVN 3121-11. "Vữa xây dựng - Phương pháp thử - Phần 11: Xác định cường độ uốn và nén của mẫu vữa đã đóng rắn," Tiêu chuẩn Việt Nam, 2003.

[16]. TCVN 8824. "Xi măng - Phương pháp xác định độ co khô của vữa," Tiêu chuần Việt Nam, 2011.

[17]. TCVN 3121-18. "Vữa xây dựng - Phương pháp thử - Phần 18: Xác định độ hút nước của mẫu vữa đã đóng rắn," Tiêu chuẩn Việt Nam, 2003

[18]. TCVN 9357. "Bê tông năng - Phương pháp thử - không phá hủy - đánh giá chất lượng bê tông bằng vận tốc xung siêu âm," Tiêu chuẩn Việt Nam, 2012.

[19]. P.Awoyera , A.Adesina. "A critical review on application of alkali activated slag as a sustainable composite binder," Case Studies in 
Construction Materials , Vol.11, pp. e00268, Dec.2019, DOI. 10.1016/j.cscm.2019.e00268.

[20]. W.Jing , J. Jiang , S.Ding , P.Duan. "Hydration and microstructure of steel slag as cementitious material and fine aggregate in mortar," Molecules , Vol.25, IS.19, pp. 4456, Jan. 2020, DOI. 10.3390/molecules25194456.

[21]. R. A.Rivera , M. Á.Sanjuán , D. A.Martín. "Granulated blast-furnace slag and coal fly ash ternary Portland cements optimization," Sustainability , Vol.12, ISS.14, pp. 5783, Jan. 2020, DOI. 10.3390/su12145783.

[22]. A.Font , L.Soriano , S. M. D. M.Pinheiro , M. M.Tashima , J.Monz , M. V.Borrachero , J.Paya. "Design and properties of $100 \%$ waste-based ternary alkali-activated mortars: Blast furnace slag, olive-stone biomass ash and rice husk ash," Journal of Cleaner Production, Vol.243, pp. 118568, Jan.2020 DOI. 10.1016/j.jclepro.2019.118568.

[23]. A.Palomo , P.Krivenko , I.Garcia-Lodeiro , E. Kavalerova , O.Maltseva , A.Fernández-Jiménez. "A review on alkaline activation: New analytical perspectives," Materiales de Construcción, Vol.64, ISS.315, pp. e022, Sep. 2014, DOI. 10.3989/mc.2014.00314.

[24]. Tống Tôn Kiên, Lê Trung Thành. "Nghiên cứu ứng suất cơ học của bê tông cốt liệu tái chế sử dụng xi măng và chất kết dính xỉ kiềm," Tạp chí Khoa học Công nghệ Xây dựng, số 5, tr. 32-36, 2017.

[25]. TCVN 4314. "Vữa xây dựng - Yêu cầu kỹ thuật," Tiêu chuẩn Việt Nam, 2003.

[26]. E. M.Kumar , K.Ramamurthy. "Influence of production on the strength, density and water absorption of aerated geopolymer paste and mortar using class F fly ash," Construction and Building Materials , Vol.156, pp. 1137-1149, Dec. 2017, DOI. 10.1016/j.conbuildmat.2017.08.153.

[27]. S. Dueramae , W.Tangchirapat , P.Chindaprasirt , C. Jaturapitakkul , P. Sukontasukkul. "Autogenous and drying shrinkages of mortars and pore structure of pastes made with activated binder of calcium carbide residue and fly ash," Construction and Building Materials , Vol.230, pp. 116962, Jan.2020, DOI. 10.1016/j.conbuildmat.2019.116962.

[28]. C. H.Jiang , J.Chen , Y. Z.Wang , S.Yan , D.Chen. "Effect of heat curing treatment on the drying shrinkage behavior and microstructure characteristics of mortar incorporating different content ground granulated blast-furnace slag," Construction and Building Materials , Vol.186, pp. 379-387, Oct. 2018, DOI. 10.1016/j.conbuildmat.2018.07.079.

[29]. B. Hassiba, M.Mekki , R. Farid. "The relationship between the compressive strength and ultrasonic pulse velocity concrete with fibers exposed to high temperatures," International Journal of Energetica , Vol.3, p. 31-36, Jun.2018, DOI. 10.47238/ijeca.v3i1.63. 